OPEN ACCESS

Edited by:

Maria Schirone,

University of Teramo, Italy

Reviewed by:

Pendru Raghunath,

Texila American University, Guyana

Giovanni Normanno,

University of Foggia, Italy

*Correspondence:

Mirella Luciani

m.luciani@izs.it

Specialty section:

This article was submitted to

Food Microbiology,

a section of the journal

Frontiers in Microbiology

Received: 18 February 2016 Accepted: 01 June 2016

Published: 15 June 2016

Citation:

Luciani M, Di Febo T, Zilli K, Di Giannatale E, Armillotta G, Manna L, Minelli F, Tittarelli M and Caprioli A (2016) Rapid Detection and Isolation of Escherichia coli 0104:H4 from Milk Using Monoclonal Antibody-coated

Magnetic Beads.

Front. Microbiol. 7:942

doi: 10.3389/fmicb.2016.00942

\section{Rapid Detection and Isolation of Escherichia coli 0104:H4 from Milk Using Monoclonal Antibody-coated Magnetic Beads}

\author{
Mirella Luciani ${ }^{1 *}$, Tiziana Di Febo'1, Katiuscia Zilli', Elisabetta Di Giannatale', \\ Gisella Armillotta ${ }^{1}$, Laura Manna ${ }^{1}$, Fabio Minelli ${ }^{2}$, Manuela Tittarelli ${ }^{1}$ and \\ Alfredo Caprioli ${ }^{2}$ \\ 'Istituto Zooprofilattico Sperimentale dell'Abruzzo e del Molise "G. Caporale", Teramo, Italy, ${ }^{2}$ EU Reference Laboratory for \\ E. coli, Department of Veterinary Public Health and Food Safety, Istituto Superiore di Sanità, Rome, Italy
}

Monoclonal antibodies (MAbs) specific for the lipopolysaccharide (LPS) of Escherichia coli O104:H4 were produced by fusion of Sp2/O-Ag-14 mouse myeloma cells with spleen cells of Balb/c mice, immunized with heat-inactivated and sonicated E. coli 0104:H4 bacterial cells. Four MAbs specific for the E. coli O104:H4 LPS (1E6G6, 1F4C9, 3G6G7, and 4G10D2) were characterized and evaluated for the use in a method for the detection of E. coli $\mathrm{O} 104: \mathrm{H} 4$ in milk samples that involves antibody conjugation to magnetic microbeads to reduce time and increase the efficiency of isolation. MAb 1E6G6 was selected and coupled to microbeads, then used for immuno-magnetic separation (IMS); the efficiency of the IMS method for E. coli O104:H4 isolation from milk was evaluated and compared to that of the EU RL VTEC conventional culturebased isolation procedure. Milk suspensions also containing other pathogenic bacteria that could potentially be found in milk (Campylobacter jejuni, Listeria monocytogenes, and Staphylococcus aureus) were also tested to evaluate the specificity of MAb-coated beads. Beads coated with MAb 1E6G6 showed a good ability to capture the E. coli O104: $\mathrm{H} 4$, even in milk samples contaminated with other bacteria, with a higher number of E. coli O104:H4 CFU reisolated in comparison with the official method (121 and $41 \mathrm{CFU}$, respectively, at $10^{3} \mathrm{E}$. coli O104:H4 initial load; 19 and $6 \mathrm{CFU}$, respectively, at $10^{2}$ E. coli O104:H4 initial load; 1 and $0 \mathrm{CFU}$, respectively, at $10^{1}$ E. coli $0104: \mathrm{H} 4$ initial load). The specificity was $100 \%$.

Keywords: detection, Escherichia coli 0104:H4, immuno-magnetic separation, milk, monoclonal antibodies

\section{INTRODUCTION}

Escherichia coli (Enterobacteriaceae) is a Gram-negative, facultative anaerobic bacterium that is commonly found in the lower intestinal tract of healthy animals and humans. However, several E. coli strains have acquired virulence traits that allow them to cause disease in humans and animals. At least six categories of pathogenic E. coli able to affect the human gut have been described: Shiga-toxin-producing E. coli, also called verocytotoxin-producing E. coli (STEC or VTEC), of which enterohaemorrhagic E. coli (EHEC) are a highly pathogenic sub-group causing 
bloody diarrhea and the hemolytic uremic syndrome (HUS), characterized by severe acute renal failure, thrombocytopenia and micro-angiopathic haemolytic anemia (European Centre for Disease Prevention and Control [ECDC] and European Food Safety Authority [EFSA], 2011); enteropathogenic E. coli (EPEC); enterotoxigenic E. coli (ETEC); enteroaggregative E. coli (EAggEC); enteroinvasive E. coli (EIEC), and attaching and effacing E. coli (A/EEC) (European Centre for Disease Prevention and Control [ECDC] and European Food Safety Authority [EFSA], 2011; Farrokh et al., 2013).

Prior to 2011, STEC serogroup O104 was not considered as a major STEC serogroup, although it had been associated with an outbreak of diarrhea in the US and with sporadic cases in European countries and Korea (European Centre for Disease Prevention and Control [ECDC] and European Food Safety Authority [EFSA], 2011; Baranzoni et al., 2014).

The concern about this serogroup increased in May-July 2011, with the occurrence of two outbreaks of bloody diarrhea and HUS in Europe: one in Germany (around 4000 cases of bloody diarrhea, 850 cases of HUS and 50 deaths), and a much smaller outbreak in southwest France (15 cases of bloody diarrhea, 9 of which progressed to HUS). Both outbreaks were caused by a STEC strain belonging to serotype O104:H4 and linked to the consumption of contaminated sprouts from fenugreek seeds (Grad et al., 2012; Baranzoni et al., 2014). The genetic analysis of the outbreak strain revealed that it carried virulence genes associated with both STEC and EaggEC (Bielaszewska et al., 2011; Scheutz et al., 2011; Baranzoni et al., 2014); in addition, all isolates also expressed the phenotypes that define STEC and EaggEC, specifically production of Shiga-toxin 2 (Stx2) and the aggregative adherence pattern on intestinal epithelial cells, and were resistant to all penicillins and cephalosporins and to co-trimoxazole (trimethoprim-sulfamethoxazole). The specific combination of the higher adherence to intestinal cells, physical survival, Stx2 production and antibiotic resistance, shows the high genomic plasticity of E. coli O104:H4 and could explain the high virulence of the epidemic strain (Bielaszewska et al., 2011; Scheutz et al., 2011).

The severity of the oubreaks caused by this foodborne pathogen highlights the need for sensitive screening methods allowing its rapid identification and isolation from food matrices, as sprouts, milk and meat.

Raw cow's and goat's milk provides a potential growth medium for bacteria and its consumption has been frequently associated with STEC infections in Europe, USA and Canada. Most of these cases were associated with STEC O157, although other serotypes or serogroups, including O22: $\mathrm{H} 8, \mathrm{O} 110: \mathrm{H}^{-}$, $\mathrm{O} 80: \mathrm{H}^{-}$, and $\mathrm{O} 145$ have been identified as causative agents. Consumption of contaminated soft and semi-soft cheeses has also been implicated in outbreaks: E. coli O157:H7 was linked to the majority of cases, but O27:H20, O103, O26, O145, O119:B14, O27:H20, and O104:H21 have also been implicated (Centers for Diseases Control and Prevention [CDC], (1995); Farrokh et al., 2013). Generally, there are two suggested routes by which potentially pathogenic STEC can contaminate raw milk: rare sub-clinical mastitis causing STEC excretion from the udder and contamination during the milking process, when teats are soiled with feces. STEC could also potentially persist if milking equipment is not adequately cleaned. Contamination of dairy products (cheeses, cream, ice-cream, yogurt and butter) is commonly due to the use of raw/unpasteurized milk, to defective pasteurization of milk and/or post processing contamination (Farrokh et al., 2013).

The aim of this work was the development of an immunomagnetic separation (IMS) method based on the use of beads coated with monoclonal antibodies (MAbs) specific for the lipopolysaccharide (LPS) of E. coli O104:H4 for the rapid and efficient isolation of E. coli O104:H4 from milk samples.

\section{MATERIALS AND METHODS}

\section{Bacterial Strains}

The E. coli O104:H4 strain used for the production and the screening of MAbs and for the immunomagnetic capture was isolated from an Italian child with HUS in 2009 (Scavia et al., 2011). Other five enteroaggregative E. coli O104 strains were used to test the MAb 1E6G6. These included two VT2-positive strains and one VT-negative strain kindly provided by the Statens Seruminstitut (Copenhagen, Denmark), a VT2-positive strain kindly provided by the Robert Koch Institute (Berlin, Germany), and another VT2-positive strain kindly provided by the Hopital Robert Debre (Paris, France). The E. coli O157, E. coli O26, E. coli O103, E. coli O111, and E. coli $\mathrm{O} 145$ strains used for MAbs characterization, were part of the culture collection of the European Union Reference Laboratory for E. coli (EU-RL-ISS). Campylobacter jejuni ATCC 33291, Listeria monocytogenes ATCC 7644, and Staphylococcus aureus ATCC 6538 used to evaluate the specificity of MAbs, were obtained from ATCC Bacterial Collection LGC.

\section{Preparation of $E$. coli Antigens for MAbs Production and Characterization}

Escherichia coli O104:H4, E. coli O157, E. coli O26, E. coli O103, E. coli O111, and E. coli O145 were grown in Brain Heart Infusion Broth (BHI) (Oxoid, Basingstoke, Hampshire, UK) at $37^{\circ} \mathrm{C}$ for 14-16 h, inactivated at $100^{\circ} \mathrm{C}$ for $1 \mathrm{~h}$ and centrifuged at $5,500 \mathrm{~g}$ for $30 \mathrm{~min}$. The pellet was washed for three times with $0.01 \mathrm{M}$ phosphate buffered saline, pH 7.2 (PBS), resuspended in PBS and stored at $-20^{\circ} \mathrm{C}$. One aliquot of the E. coli O104:H4 suspension was sonicated in ice bath for two cycles of $2.5 \mathrm{~min}$ each with an interval of $5 \mathrm{~min}$ and immediately used for mice immunization.

The protein concentration of antigen preparations was determined using the BCA Protein Assay Kit (Pierce Rockford, IL, USA).

\section{Preparation of the E. coli 0104 Lipopolysaccharide}

The E. coli O104 LPS was extracted by the hot phenol-water method (Westphal and Jann, 1965). The LPS was precipitated with $3 \mathrm{M}$ sodium-acetate and absolute ethanol, ultracentrifuged, resuspended in deionized water and stored at $-80^{\circ} \mathrm{C}$ until 
use. The quantity of LPS was determined by the 2-keto-3deoxyoctonate (KDO) assay (Karkharis et al., 1978).

\section{Immunization of Mice}

For MAbs production, 6/8 week-old Balb/c mice were inoculated with heat-inactivated and sonicated $E$. coli $\mathrm{O} 104: \mathrm{H} 4$ preparations. Animal experimentation was carried out in compliance with Italian national law (Decreto legislativo 27 Gennaio, 1992, n. 116) implementing Directive $86 / 609 /$ EEC of the Council of the European Communities on the protection of animals used for experimental and other scientific purposes (European Commission [EC], 1986). The protocol was approved by the Italian Ministry of Health with number 5146 of 26.04.2012. The whole antigen, diluted to a protein concentration of $100 \mu \mathrm{g} / \mathrm{ml}$, was emulsified with complete Freund adjuvant (Sigma, St. Louis, MO, USA) and administered intraperitoneally; 14 days later a second immunization was performed using the same concentration of antigen emulsified with incomplete Freund adjuvant (Sigma). Subsequently, on days 28 and 56, $100 \mu \mathrm{g} / \mathrm{ml}$ of antigen diluted in PBS was given (intravenous booster). Three days later, the mice were sacrificed, the spleen collected and splenocytes subjected to cell fusion with murine myeloma cells Sp2/O-Ag-14 (ATCC CRL-1581 ${ }^{\mathrm{TM}}$ ).

\section{Characterization of Monoclonal Antibodies vs. E. coli O104:H4}

The antibody-secreting hybridomas, cultured in Dulbecco's Modified Eagle's Medium (DMEM) containing 20\% bovine fetal serum, 2 mM L-glutamine, 100X Penicillin-StreptomycinAmphotericin, $50 \mathrm{mg} / \mathrm{ml}$ gentamicin and 50X HAT, were screened by i-ELISA. Briefly, 96-well microplates (PolySorp, Nunc Brand Products, Roskilde, DK) were coated with $10 \mu \mathrm{g} / \mathrm{ml}$ of E. coli O104 LPS and of the bacterial whole antigens (E. coli O104:H4, E. coli O157, E. coli O26, E. coli O103, E. coli O111, E. coli $\mathrm{O} 145$ ) diluted in $0.05 \mathrm{M}$ carbonate-bicarbonate buffer, $\mathrm{pH}$ 9.6, and incubated overnight at $4^{\circ} \mathrm{C}$. After washing and blocking with $1 \%$ yeast extract in PBS containing $0.05 \%$ Tween 20 (PBST) at $37^{\circ} \mathrm{C}$ for $1 \mathrm{~h}, 100 \mu \mathrm{l} /$ well of MAbs supernatants were added and incubated for $1 \mathrm{~h}$ at $37^{\circ} \mathrm{C}$. As secondary antibody, ECL anti-mouse IgG conjugated with horseradish peroxidase (GE Healthcare, Little Chalfont, Buckinghamshire, UK) was used; the $3,3^{\prime}, 5,5^{\prime}$-tetramethylbenzidine (TMB, Sigma) was adopted as chromogenic substrate. Microplate reading was performed with a biophotometer (Bio-Rad, Hercules, CA, USA) at a wavelength of $450 \mathrm{~nm}$. Clones that showed optical densities $\left(\mathrm{OD}_{450}\right)$ greater than or equal to 3 times the $\mathrm{OD}_{450}$ of the negative control (serum of a naive Balb/c mouse) were considered as positives and were cloned by the limiting dilution method (Luciani et al., 2006). MAbs were produced in vitro on a large scale by means of serial cultures of hybridomas and collection of the supernatants and were isotyped using the Mouse-Typer Isotyping Panel (Bio-Rad).

For immunoblotting analysis, MAbs with IgG and IgM isotype were purified on affinity chromatography using, respectively, a HiTrap rProtein A FF column (GE Healthcare, Uppsala, SW) and a HiTrap IgM Purification HP column (GE Healthcare), according to the manufacturer's instructions.
Purified MAbs were concentrated with $100 \mathrm{kDa}$ cutoff centrifugal filters (Millipore, Billerica, MA, USA) and resuspended in PBS. The protein concentration of purified MAbs was determined by spectrophotometry (Absorbance at $280 \mathrm{~nm} /$ IgG molar extinction coefficient).

The heat-treated E. coli O104:H4 suspensions $(2.5 \mu \mathrm{g} /$ well $)$ were subjected to SDS-PAGE separation at $200 \mathrm{~V}$ with NuPAGE 4-12\% Bis-Tris Gels Mini (Novex, Life Technologies, Carlsbad, CA, USA) and transferred onto nitrocellulose membrane with iBlot Dry Blotting System (Life Technologies). After blocking with 5\% skimmed milk (Fluka Analytical, Sigma-Aldrich) in PBST for $2 \mathrm{~h}$ at room temperature (RT), membrane strips were incubated overnight at $4^{\circ} \mathrm{C}$ with the purified MAbs. The detection of immune complexes was performed using the ECL anti-mouse IgG HRP-conjugated (GE Healthcare) and a chemiluminescent substrate (ECL Select Western Blotting Detection Reagent, GE Healthcare). The analysis of the results was performed using the Chemidoc MP (Bio-Rad) and the Quantity One Quantitation Software version 4.3 (Bio-Rad).

\section{Magnetic Beads Coupling Procedure}

Purified MAbs were coupled to Dynabeads M-450 Tosylactivated (Life Technologies). Twenty-five micro litre of dynabeads were first washed with $0.1 \mathrm{M}$ sodium phosphate buffer, $\mathrm{pH} 7.4$, and then incubated with $5 \mu \mathrm{g}$ of each purified $\mathrm{MAb}$ at $37^{\circ} \mathrm{C}$ for $24 \mathrm{~h}$ using the Dynabeads MX4 Mixer (Life Technologies). Supernatant was removed and dynabeads were resuspended in $0.1 \mathrm{M}$ Tris containing $0.1 \%$ BSA ( $\mathrm{pH} 8.5$ ) and incubated for $4 \mathrm{~h}$ at $37^{\circ} \mathrm{C}$ with gentle and continuous agitation. Supernatant was discarded and activated dynabeads were resuspended in PBS containing $0.1 \%$ BSA, 2 mM EDTA (pH 7.4), and stored at $4^{\circ} \mathrm{C}$ until use.

Non-coated dynabeads were also prepared using the same protocol, but without the incubation with the MAbs (noncoated-beads control as blank).

\section{Preparation of Bacterial Strains for Immuno-Magnetic Separation}

Escherichia coli O104:H4 was grown in Tryptic Soy Broth (TSB) (Becton Dickinson, Franklin Lakes, NJ, USA) for $24 \mathrm{~h}$ at $37^{\circ} \mathrm{C}$, and then the cultures were streaked onto Tryptic Soy Agar (TSA) (Becton Dickinson) plates and incubated for $24 \mathrm{~h}$ in aerobic atmosphere at $37^{\circ} \mathrm{C}$. A well separated colony from the plate was transferred into $10 \mathrm{ml}$ of TSB and incubated at $37^{\circ} \mathrm{C}$ in order to obtain a bacterial suspension with a turbidity between 2 and 3 McFarland standards. The number of cells in the bacterial suspension was also estimated by reading the absorbance at $600 \mathrm{~nm}\left(\mathrm{OD}_{600}\right)$. The final concentration of bacterial suspension was $10^{11}$ CFU. The culture was decimally diluted in sterile PBS (until $10^{-11}$ ); the number of bacteria in each diluted suspension was confirmed by plating onto MacConkey Agar at $37^{\circ} \mathrm{C}$ for $24 \mathrm{~h}$.

Campylobacter jejuni, L. monocytogenes, and S. aureus (pool of contaminating bacteria) were grown, respectively, on Karmali Agar, Aloe Agar, and TSA Agar. For each strain, a bacterial suspension in PBS with a concentration of $0.8 \mathrm{McF}$ arland (about $\left.10^{8} \mathrm{CFU}\right)$ was prepared. 


\section{Immuno-Magnetic Separation and Evaluation of MAb-Coated Beads Specificity}

The specificity of MAb-coated beads was first evaluated using PBS suspensions, prepared as described above, containing decreasing concentration of E. coli O104:H4 from $10^{6} \mathrm{CFU}$ to $10^{1}$ CFU. Tests were repeated using E. coli O104:H4 PBS suspensions containing L. monocytogenes, C. jejuni and S. aureus at the concentration of $10^{3} \mathrm{CFU}$ each.

One $\mathrm{ml}$ of each PBS-diluted bacterial suspension was added with $25 \mu \mathrm{l}$ of MAb-activated dynabeads and incubated at $4^{\circ} \mathrm{C}$ for 30 min with gentle and continuous agitation. Then, dynabeads were washed four times with PBS containing $0.1 \%$ BSA and $2 \mathrm{mM}$ EDTA, ( $\mathrm{pH} 7.4$ ), resuspended in $100 \mu \mathrm{l}$ of PBS, plated onto MacConkey Agar plates and incubated at $37^{\circ} \mathrm{C}$ for $24 \mathrm{~h}$. The same

TABLE 1 | Monoclonal antibodies isotypes.

\begin{tabular}{ll}
\hline Clone & Isotype \\
\hline 1E6G6 & IgG1 anti $\kappa$ \\
1F4C9 & IgG3 anti $\kappa$ \\
$3 G 6 G 7$ & IgG1 anti $\kappa$ \\
$4 G 10 D 2$ & IgG3 anti $\kappa$
\end{tabular}

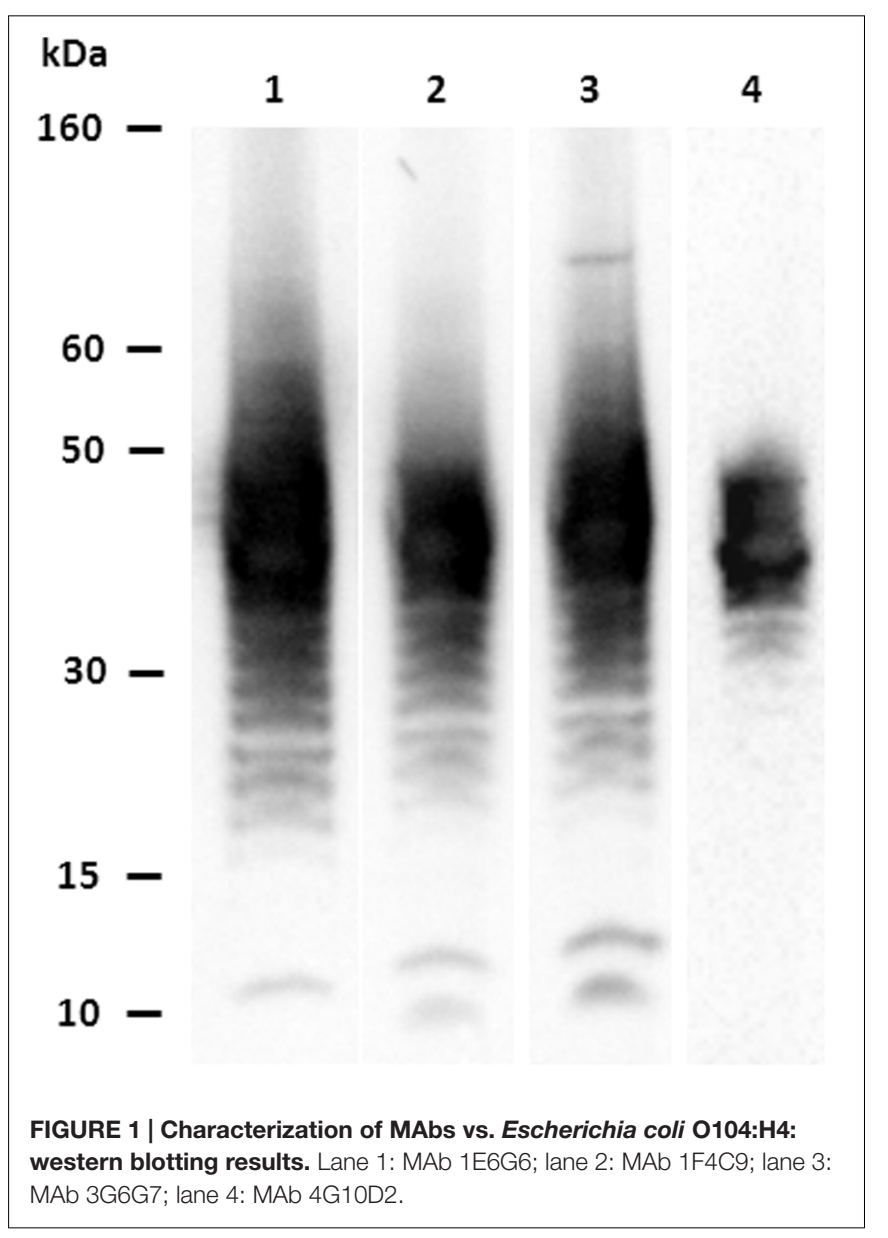

procedure was repeated using non-coated beads to ensure the absence of aspecific interactions between the non-coated beads and bacteria.

\section{Inoculation and Enrichment of Milk and E. coli 0104:H4 Detection from Artificially Contaminated Milk Samples}

Six aliquots ( $9 \mathrm{ml}$ each) of bovine raw milk were artificially contaminated with $1 \mathrm{ml}$ of each one of the six bacterial suspensions previously prepared (E. coli O104:H4 concentration from $10^{6} \mathrm{CFU}$ to $\left.10^{1} \mathrm{CFU}\right)$. One $\mathrm{ml}$ of each E. coli O104:H4 contaminated milk sample was incubated with MAb-coated and non-coated beads as described above. In the same time, one $\mathrm{ml}$ aliquot of each milk sample was analyzed using the EU RL VTEC official method, which include an overnight enrichment step. Aliquots $(100 \mu \mathrm{l})$ of the IMS-treated samples and of the enrichment broth cultures prepared according to the EU RL VTEC method were plated onto MacConkey Agar plates. After incubation for $24 \mathrm{~h}$ at $37^{\circ} \mathrm{C}$ in aerobic condition, the colonies obtained with the EU RL VTEC method and with MAb-coated beads were enumerated.

To verify the absence of cross-reaction between MAbs and bacteria other than E. coli O104:H4, the same tests described above were repeated using four aliquots for each of the six cream milk samples artificially contaminated with the six bacterial suspensions at the concentration of E. coli O104:H4 from $10^{6}$ CFU to $10^{1} \mathrm{CFU}$ and with each species of contaminating bacteria at the concentration of $10^{3} \mathrm{CFU}$. Each of four aliquots of the six milk suspensions were, respectively, plated onto MacConkey Agar, onto Blood Agar for $24 \mathrm{~h}$ at $37^{\circ} \mathrm{C}$ in aerobic condition for L. monocytogenes and S. aureus isolation, and Karmali Agar for $48 \mathrm{~h}$ at $42^{\circ} \mathrm{C}$ in microaerobic conditions for C. jejuni isolation.

\section{DNA Extraction and PCR for Strains Typing}

Escherichia coli O104:H4 DNA extraction was performed using the InstaGene Matrix (Bio-Rad) according to manufacturer's instructions. Primers used for the PCR assay were specific for the $r f b_{\mathrm{O} 104}$ gene, encoding the O-antigen specific for E. coli $\mathrm{O} 104$ (O104rfbO-f 5' TGAACTGATTTTTAGGATGG 3'; O104rfbOr 5' AGAACCTCACTCAAATTATG 3', amplicon size $351 \mathrm{bp)}$ (Bielaszewska et al., 2011). A $50 \mu \mathrm{l}$ PCR mixture contained: $25 \mu 12 \times$ TopTaq Master Mix (Qiagen, Venlo, NL) (1.25 units of TopTaq DNA Polymerase, $1 \times$ PCR buffer, dNTPs concentration $0.2 \mathrm{mM}$ each, $1.5 \mathrm{mM} \mathrm{MgCl}_{2}$ ), $1 \mu \mathrm{l}$ of each primer at the concentration of $0.2 \mu \mathrm{M}, 18 \mu \mathrm{l}$ of Nuclease-Free Water and $5 \mu \mathrm{l}$ of template DNA. Amplifications were performed using the GeneAmp ${ }^{\circledR}$ PCR System 9700 (Applied Biosystems, Life Technologies) and the following temperature cycling conditions: initial denaturation at $95^{\circ} \mathrm{C}$ for $5 \mathrm{~min}$, followed by 35 cycles of denaturation at $95^{\circ} \mathrm{C}$ for 30 seconds, annealing at $55^{\circ} \mathrm{C}$ for $1 \mathrm{~min}$, extension at $72^{\circ} \mathrm{C}$ for $1 \mathrm{~min}$ and final extension at $72^{\circ} \mathrm{C}$ for $7 \mathrm{~min}$. The PCR products were resolved by electrophoresis on a $1,5 \%$ agarose gel. 
TABLE 2 | Evaluation of MAb-coated beads specificity using Escherichia coli 0104:H4 PBS pure suspensions.

\begin{tabular}{lc}
$\begin{array}{l}\text { E. coli 0104:H4 in the } \\
\text { initial suspension } \\
\text { (CFU number) }\end{array}$ & $\begin{array}{r}\text { E. coli O104:H4 re-isolated after } \\
\text { immuno-magnetic separation (IMS) } \\
\text { (CFU number) }\end{array}$ \\
\hline $10^{6}$ & $>200$ \\
$10^{5}$ & $>200$ \\
$10^{4}$ & $>200$ \\
$10^{3}$ & 76 \\
$10^{2}$ & 3 \\
$10^{1}$ & 0 \\
\end{tabular}

\section{Statistical Analysis}

In order to determine differences between the EU RL VTEC conventional culture-based isolation procedure and the IMS method described in this paper, the Wilcoxon test for dependent samples was applied (confidence interval $=95 \%$ ).

\section{RESULTS}

\section{Characterization of Monoclonal Antibodies vs. the LPS of E. coli 0104:H4}

A total of 28 hybridomas were positive against the E. coli O104:H4 whole heat-treated antigen in indirect ELISA. Four MAbs (1E6G6, 1F4C9, 3G6G7, and 4G10D2) were found positive for both the E. coli O104:H4 LPS and whole antigen, and negative against the other $\mathrm{O}$ serogroups tested. MAbs isotypes are shown in Table 1. Characterization by western blotting revealed that the four selected MAbs reacted with the LPS of E. coli O104:H4; Figure 1 shows the ladder-like pattern of LPS bands with molecular weights between 60 and $15 \mathrm{kDa}$ recognized by the MAbs. One of the four selected MAbs, MAb 1E6G6, was tested by slide agglutination against five additional E. coli O104:H4 strains with positive results and subsequently conjugated to magnetic microbeads, to be used for a specific IMS of E. coli O104:H4 from milk samples.

\section{Immuno-Magnetic Separation and Evaluation of MAb-Coated Beads Specificity}

The results obtained from E. coli O104:H4 re-isolation from PBS pure bacterial suspensions are shown in Table 2. At E. coli concentrations higher than or equal to $10^{4}$, the number of CFU re-isolated was higher than 200. At the concentrations of $10^{3}$ and $10^{2} \mathrm{CFU}, 76$ and $3 \mathrm{CFU}$, respectively, were re-isolated following the IMS.

When the E. coli O104:H4 PBS suspensions containing other bacteria (L. monocytogenes, C. jejuni and S. aureus) were used, more than 200 E. coli O104:H4 CFU were re-isolated from suspensions with $E$. coli concentrations higher than or equal to $10^{3} ; 19$ and $2 \mathrm{CFU}$ were re-isolated from the $10^{2}$ and $10^{1} \mathrm{CFU}$ E. coli O104:H4 suspensions, respectively, (Table 3). None of the contaminating bacteria were captured by the MAb-coated beads.
No aspecific binding between the non-coated beads and the four bacterial suspensions used in the experiments was observed.

\section{E. coli 0104:H4 Detection in Artificially Contaminated Milk Samples}

Table 4 shows the results of the E. coli O104:H4 isolation from milk samples contaminated with scalar dilutions (from $10^{6}$ to $10^{1} \mathrm{CFU}$ ) of E. coli O104:H4. With the Dynabeads method, a higher number of E. coli O104:H4 CFU was isolated with respect to the EU RL method. Similar results were obtained with milk samples contaminated with E. coli O104:H4 and with other bacteria (L. monocytogenes, C. jejuni and S. aureus) (Table 5). The $\mathrm{p}$-value obtained using the Wilcoxon test for dependent samples was 0.0517 with a confidence interval of $95 \%$.

Moreover, none of the other contaminating bacteria were captured by MAb-coated beads, as shown by the absence of growth in the specific media. MAb-coated beads isolates were further confirmed by PCR: all the bacteria captured by coated beads were E. coli O104:H4 (Figure 2).

\section{DISCUSSION AND CONCLUSION}

Shiga toxin-producing Escherichia coli strains are important foodborne pathogens that have been responsible for numerous

TABLE 3 | Evaluation of MAb-coated beads specificity using E. coli 0104:H4 PBS suspensions containing contaminating bacteria (Listeria monocytogenes, Campylobacter jejuni, and Staphylococcus aureus).

\begin{tabular}{lccc}
\hline $\begin{array}{l}\text { E. coli } \\
\text { O104:H4 in } \\
\text { the initial } \\
\text { suspension } \\
\text { (CFU number) }\end{array}$ & $\begin{array}{c}\text { Contaminating } \\
\text { bacteria in the } \\
\text { initial } \\
\text { suspension } \\
\text { (CFU number) }\end{array}$ & $\begin{array}{c}\text { E. coli O104:H4 } \\
\text { re-isolated after } \\
\text { IMS (CFU } \\
\text { number) }\end{array}$ & $\begin{array}{c}\text { Contaminating } \\
\text { bacteria } \\
\text { re-isolated after } \\
\text { IMS (CFU } \\
\text { number) }\end{array}$ \\
\hline $10^{6}$ & $10^{3}$ & $>200$ & 0 \\
$10^{5}$ & $10^{3}$ & $>200$ & 0 \\
$10^{4}$ & $10^{3}$ & $>200$ & 0 \\
$10^{3}$ & $10^{3}$ & $>200$ & 0 \\
$10^{2}$ & $10^{3}$ & 19 & 0 \\
$10^{1}$ & $10^{3}$ & 2 & 0
\end{tabular}

TABLE 4 | Escherichia coli 0104:H4 isolation from artificially contaminated milk samples in the absence of contaminating bacteria: comparison between the EU RL VTEC official method and the E. coli 0104 Dynabeads method.

\begin{tabular}{lcc}
\hline $\begin{array}{l}\text { E. coli O104:H4 in } \\
\text { the initial } \\
\text { suspension (CFU } \\
\text { number) }\end{array}$ & $\begin{array}{c}\text { E. coli O104:H4 } \\
\text { isolated with the } \\
\text { EU RL method } \\
\text { (CFU number) }\end{array}$ & $\begin{array}{c}\text { E. coli O104:H4 } \\
\text { isolated with the } \\
\text { O104 Dynabeads } \\
\text { method (CFU } \\
\text { number) }\end{array}$ \\
\hline $10^{6}$ & $>200$ & $>200$ \\
$10^{5}$ & 159 & $>200$ \\
$10^{4}$ & 117 & $>200$ \\
$10^{3}$ & 43 & $>200$ \\
$10^{2}$ & 8 & 27 \\
$10^{1}$ & 0 & 4
\end{tabular}


TABLE 5 | Escherichia coli O104:H4 detection from artificially contaminated milk samples in the presence of contaminating bacteria (L. monocytogenes, C. jejuni, and S. aureus): comparison between the EU RL VTEC official method and the E. coli O104 Dynabeads method.

\begin{tabular}{|c|c|c|c|c|c|c|}
\hline $\begin{array}{l}\text { E. coli 0104:H4 in } \\
\text { the initial } \\
\text { suspension (CFU } \\
\text { number) }\end{array}$ & $\begin{array}{l}\text { Contaminating } \\
\text { bacteria in the } \\
\text { initial suspension } \\
\text { (CFU number) }\end{array}$ & $\begin{array}{c}\text { E. coli 0104:H4 } \\
\text { isolated with EU } \\
\text { RL method (CFU } \\
\text { number) }\end{array}$ & $\begin{array}{c}\text { E. coli 0104:H4 } \\
\text { isolated with the } \\
\text { E. coli } 0104 \\
\text { Dynabeads } \\
\text { method (CFU } \\
\text { number) }\end{array}$ & $\begin{array}{l}\text { S. aureus isolated } \\
\text { with the E. coli } \\
\text { O104 Dynabeads } \\
\text { method (CFU } \\
\text { number on Blood } \\
\text { Agar plate) }\end{array}$ & $\begin{array}{c}\text { L. monocytogenes } \\
\text { isolated with the } \\
\text { E. coli O104 } \\
\text { Dynabeads } \\
\text { method (CFU } \\
\text { number on Blood } \\
\text { Agar plate) }\end{array}$ & $\begin{array}{c}\text { C. jejuni isolated } \\
\text { with the E. coli } \\
\text { O104 Dynabeads } \\
\text { method (CFU } \\
\text { number on } \\
\text { Karmali Agar } \\
\text { plate) }\end{array}$ \\
\hline $10^{6}$ & $10^{3}$ & $>200$ & $>200$ & 0 & 0 & 0 \\
\hline $10^{5}$ & $10^{3}$ & $>200$ & $>200$ & 0 & 0 & 0 \\
\hline $10^{4}$ & $10^{3}$ & 137 & $>200$ & 0 & 0 & 0 \\
\hline $10^{3}$ & $10^{3}$ & 41 & 121 & 0 & 0 & 0 \\
\hline $10^{2}$ & $10^{3}$ & 6 & 19 & 0 & 0 & 0 \\
\hline $10^{1}$ & $10^{3}$ & 0 & 1 & 0 & 0 & 0 \\
\hline
\end{tabular}

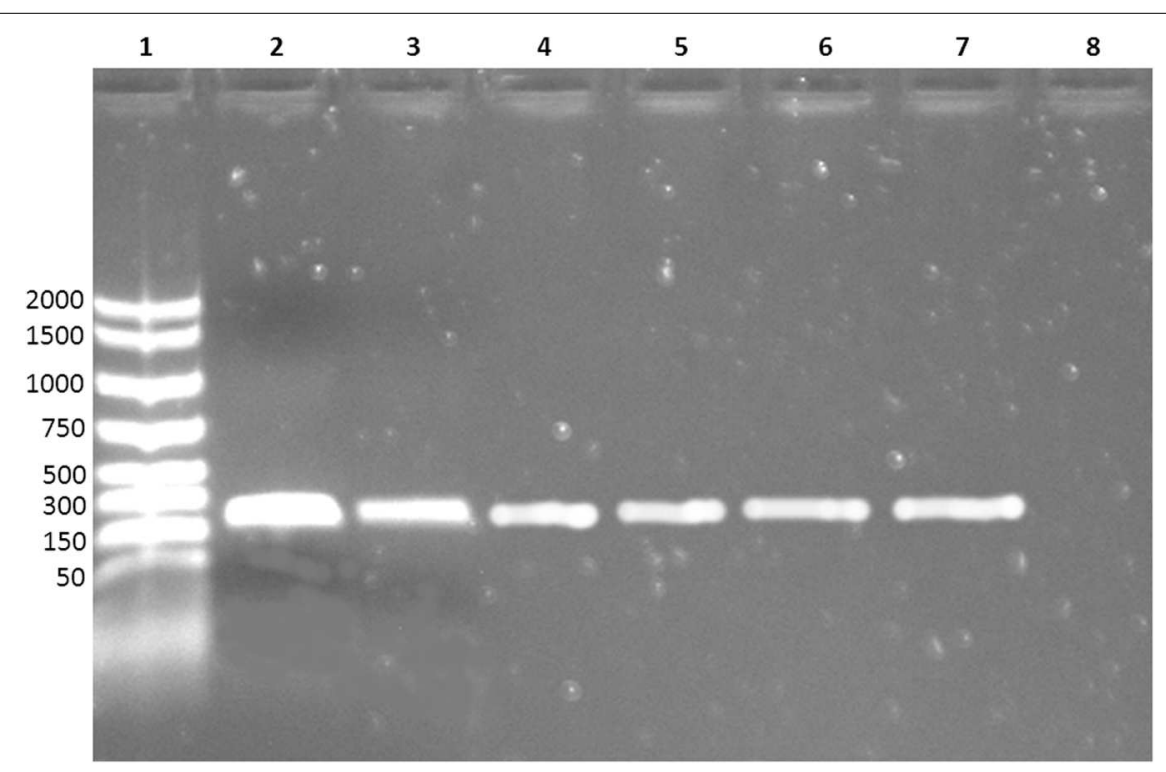

FIGURE 2 | Electrophoresis of the PCR products. Lane 1: molecular weight marker; lane 2-6: E. coli O104:H4 captured by MAb-coated magnetic beads; lane 7: positive control (DNA extracted from E. coli O104:H4 ISS-certified); lane 8: negative control (nuclease-free water).

outbreaks of hemorrhagic colitis and HUS worldwide. E. coli O157:H7 is the most frequently implicated in human disease, although infections can be caused by other serotypes or serogroups, as E. coli O104:H4. Consequently it is necessary to have the availability of rapid, sensitive and specific methods for food control.

In this study, MAbs vs. E. coli O104:H4 were produced andcharacterized. The efficiency of the E. coli O104:H4 isolation from milk samples, using Dynabeads activated with a selected MAb (1E6G6) specific for E. coli O104:H4 LPS, was evaluated and compared with that of the EU RL VTEC isolation procedure (European Reference Laboratory for E.coli [EU-RL VTEC], 2011). The specificity of the adsorbed antibodies was also evaluated by preparing E. coli O104:H4 suspensions containing other pathogenic bacteria that could potentially be found in milk, such as Campylobacter jejuni, Listeria monocytogenes, and Staphylococcus aureus (Farrokh et al., 2013).
The use of MAbs, instead of polyclonal ones (PAbs), could be a valid alternative to improve the specificity of pathogen detection. PAbs may have a lack of homogeneity between lots, due to the variability of the animal immune response. They may also show cross-reactions with related pathogens. Conversely, MAbs are highly specific reagents, easily purified and with batch to batch homogeneity.

Immuno-magnetic separation is a rapid and sensitive method that permit the revelation of low concentrations of pathogens in contaminated matrices. The magnetic beads method has already been applied for the detection of E. coli O157:H7 (Weagant et al., 2011) and E. coli O104 (Baranzoni et al., 2014) from sprouts with good results. In particular, Baranzoni et al. (2014) used commercially available E. coli IMS beads in association with optimized enrichment conditions of sprouts samples. The results indicated that the IMS enrichment enhanced the ability to detect E. coli $\mathrm{O} 104$ and reduced the interference 
of background microflora. In our work, we used O104-specific magnetic beads prepared in-house to detect this pathogen in artificially contaminated milk samples, skipping the use of a previous enrichment step. The procedure showed an analytical sensitivity higher than that of the isolation procedure included in the official EURL method for E. coli O104. Even if the statistic analysis gave a value slightly higher than the expected one, numeric data show that the immunomagnetic method is more sensitive, particularly at low concentrations of bacteria.

The MAb-coated beads showed a good capability to capture E. coli O104:H4 in artificially contaminated milk samples, even in the presence of other contaminating bacteria, such as C. jejuni, L. monocytogenes, and S. aureus, with an increase in the number of CFU re-isolated with respect to the current official method ( $>200$ and $137 \mathrm{CFU}$, respectively, at $10^{4} \mathrm{E}$. coli O104:H4 initial load; 121 and $41 \mathrm{CFU}$, respectively, at $10^{3} \mathrm{E}$. coli O104:H4 initial load; 19 and $6 \mathrm{CFU}$, respectively, at $10^{2}$ E. coli O104:H4 initial load and 1 and 0 CFU, respectively, at $10^{1}$ E. coli O104:H4 initial load). The Dynabeads method also showed a good analytical specificity, since no contaminating bacteria were captured by the MAb-coated beads in both PBS bacterial suspensions and contaminated milk samples and no

\section{REFERENCES}

Baranzoni, G. M., Fratamico, P. M., Rubio, F., Glaze, T., Bagi, L. K., and Albonetti, S. (2014). Detection and isolation of Shiga toxin-producing Escherichia coli (STEC) O104 from sprouts. Int. J. Food Microbiol. 173, 99-104. doi: 10.1016/j.ijfoodmicro.2013.12.020

Bielaszewska, M., Mellmann, A., Zhang, W., Köck, R., Fruth, A., Bauwens, A., et al. (2011). Characterisation of the Escherichia coli strain associated with an outbreak of haemolytic uraemic syndrome in Germany, 2011: a microbiological study. Lancet Infect. Dis. 11, 671-676. doi: 10.1016/S1473-3099(11)70165-7

Centers for Diseases Control and Prevention [CDC] (1995). Outbreak of acute gastroenteritis attributable to Escherichia coli serotype O104:H21 - Helena, Montana, 1994. MMWR Morb. Mortal. Wkly. Rep. 44, 501-503.

Decreto legislativo 27 Gennaio (1992). n. 116. Attuazione della direttiva n. 86/609/CEE in materia di protezione degli animali utilizzati a fini sperimentali o ad altri fini scientifici. Official J. 40, 1-32.

European Centre for Disease Prevention and Control [ECDC] and European Food Safety Authority [EFSA] (2011). Shiga Toxin/Verotoxin-Producing Escherichia coli in Humans, Food and Animals in the EU/EEA, with Special Reference to the German Outbreak Strain STEC O104. ECDC/EFSA Joint Technical Report (Stockolm: ECDC), 1-18.

European Commission [EC] (1986). Council Directive of 24 November 1986 on the approximation of laws, regulations and administrative provisions of the Member States regarding the protection of animals used for experimental and other scientific purposes (86/609/EEC). Official J. L358, 1-28.

European Reference Laboratory for E.coli [EU-RL VTEC] (2011). Detection and Identification of Verocytotoxin-Producing Escherichia coli (VTEC) 0104:H4 in food by Real Time PCR. Rome: Istituto Superiore di Sanità.

Farrokh, C., Jordan, K., Auvray, F., Glass, K., Oppegaard, H., Raynaud, S., et al. (2013). Review of Shiga-toxin-producing Escherichia coli (STEC) and their significance in dairy production. Int. J. Food Microbiol. 162, 190-212. doi: 10.1016/j.ijfoodmicro.2012.08.008

Grad, Y. H., Lipsitch, M., Feldgarden, M., Arachchi, H. M., Cerqueira, G. C., Fitzgerald, M., et al. (2012). Genomic epidemiology of the Escherichia coli O104:H4 outbreaks in Europe, 2011. Proc. Natl. Acad. Sci. U.S.A. 109, 30653070. doi: 10.1073/pnas.1121491109 aspecific reactions were obtained with non-coated beads. MAb 1E6G6 was able to retain its antigen-binding activity even in the presence of a fat matrix such as full cream milk. Moreover, the direct application of the O104 IMS to a liquid matrix such as milk, skipping the broth enrichment step that requires an overnight incubation period, allowed a more rapid isolation of E. coli O104, with respect to the current official method.

Thus, magnetic beads linked with the MAb 1E6G6 against E. coli $\mathrm{O} 104: \mathrm{H} 4$ could be a useful tool for improving the detection of this E. coli serogroup in milk samples. Further studies are needed to evaluate the performances of MAb 1E6G6 coatedbeads when matrices other than from milk are tested.

\section{AUTHOR CONTRIBUTIONS}

ML, TD, and AC designed the study; ML, TD, GA, LM, FM, and MT produced, characterized and purified monoclonal antibodies; $\mathrm{AC}, \mathrm{FM}, \mathrm{KZ}$, and ED performed microbiological analysis; ML coordinated animal management; ML, TD, and KZ drafted the manuscript; AC, ED, and MT revised the paper critically. All authors read and approved the final version of the manuscript.

Karkharis, Y. D., Zeltner, J. Y., Jackson, J. J., and Carlo, D. J. (1978). A new and improved microassay to determine 2-keto-3-deoxyoctonate in lipopolysaccharide of gram-negative bacteria. Anal. Biochem. 85, 595-601. doi: 10.1016/0003-2697(78)90260-9

Luciani, M., Armillotta, G., Magliulo, M., Portanti, O., Di Febo, T., Di Giannatale, E., et al. (2006). Production and characterization of monoclonal antibodies specific for Escherichia coli O157:H7. Vet. Ital. 42, 173-182.

Scavia, G., Morabito, S., Tozzoli, R., Michelacci, V., Marziano, M. L., Minelli, F., et al. (2011). Similarity of Shiga toxin-producing Escherichia coli O104:H4 strains from Italy and Germany. Emerg. Infect. Dis. 17, 1957-1958. doi: 10.3201/eid1710.111072

Scheutz, F., Nielsen, E. M., Frimodt-Møller, J., Boisen, N., Morabito, S., Tozzoli, R., et al. (2011). Characteristics of the enteroaggregative Shiga toxin/verotoxinproducing Escherichia coli O104:H4 strain causing the outbreak of haemolytic uraemic syndrome in Germany, May to June 2011. Euro Surveill. 16, 5-10.

Weagant, S. D., Jinneman, K. C., Yoshitomi, K. J., Zapata, R., and Fedio, W. M. (2011). Optimization and evaluation of a modified enrichment procedure combined with immunomagnetic separation for detection of E. coli O157:H7 from artificially contaminated alfalfa sprouts. Int. J. Food Microbiol. 149, 209217. doi: 10.1016/j.ijfoodmicro.2011.06.008

Westphal, O., and Jann, K. (1965). Bacterial lipopolysaccharides, extraction with phenol-water and further application of the procedure. Methods Carbohydr. Chem. 5, 83-91.

Conflict of Interest Statement: The authors declare that the research was conducted in the absence of any commercial or financial relationships that could be construed as a potential conflict of interest.

Copyright (c) 2016 Luciani, Di Febo, Zilli, Di Giannatale, Armillotta, Manna, Minelli, Tittarelli and Caprioli. This is an open-access article distributed under the terms of the Creative Commons Attribution License (CC BY). The use, distribution or reproduction in other forums is permitted, provided the original author(s) or licensor are credited and that the original publication in this journal is cited, in accordance with accepted academic practice. No use, distribution or reproduction is permitted which does not comply with these terms. 